Fiscaoeconomia

E-ISSN: 2564-7504

2021, Volume 5, Issue 3, 1175-1190

https://dergipark.org.tr/tr/pub/fsecon
Research Article/Araştırma Makalesi

Submitted/Geliş: 14.08 .2021

Accepted/Kabul: 10.09.2021

Doi: $10.25295 /$ fsecon. 982890

\title{
Türkiye'nin Dış Ticaretinde J Eğrisi Hipotezinin Analizi
}

The Analysis of J Curve Hypothesis on Turkey's Foreign Trade

\section{Hakan GÜNEŞ ${ }^{1}$}

\section{Öz}

J eğrisi hipotezi, döviz kuru müdahalesiyle birlikte dış ticaret dengesinin kısa dönemde kötüleşeceğini, uzun dönemde ise iyileşeceğini ifade etmektedir. Hipoteze göre, kısa dönemde döviz kurundaki fiyat değişmelerine tepki hemen gerçekleşmeyeceğinden dış ticaret bilançosu bozulacaktır. Ancak uzun dönemde fiyat uyarlamalarından dolayı dış ticaret dengesi iyileşecektir. Uzun dönemde dış ticaret dengesinin iyileşmesinin nedeni, Marshall-Lerner koşuluna dayanmaktadır. ìracat ve ithalat fiyat esnekliğinin toplamının 1'den büyük olmasını ifade eden Marshall-Lerner koşulu, J eğrisinin temelini oluşturmaktadır.

Bu çalışmada, Türkiye'de J eğrisi hipotezinin geçerli olup olmadığı incelenmiştir. Ocak 2010-Eylül 2019 dönemi için aylık zaman serisini içeren verilerle, kısa ve uzun dönem nedensellik, eşbütünleşme ve ilişkinin sapmasız katsayılarını gösteren FMOLS testleri yapılmıştır. Yapılan analiz sonucunda, kısa dönemde reel efektif döviz kuru ihracatın bir nedeni değildir. Bu yüzden Türkiye'de J eğrisi hipotezinin geçerli olmadığı kanıtına ulaşılmışır. Ancak kısa dönemde reel efektif döviz kuru ithalatın bir nedenidir. Uzun dönemde ise reel döviz kuru ile ihracat ve ithalat arasında nedensel bir ilişki mevcuttur. Değişkenler 1.farkta durağan olduğu için Johansen eşbütünleşme testi yapılmış ve reel efektif döviz kuruyla ihracat ve ithalat arasında uzun dönemli bir ilişki tespit edilmiştir. Yapılan FMOLS tahmincisine göre, reel efektif döviz kurundaki 1 birimlik artışın ihracatı 0,33 birim ve ithalatı da 0,439 birim arttırmaktadır. Bu durum uzun dönemde Türkiye'de dış ticaret açıklarının devam edeceğine işaret etmektedir.

Jel Kodları: F1, E4, E5.

Anahtar Kelimeler: J eğrisi, Döviz Kuru, ihracat, ithalat, Johansen testi.

1 Öğretim Görevlisi Dr., Bartın Üniversitesi Bartın Meslek Yüksekokulu Muhasebe ve Vergi Bölümü, hakangunes@bartin.edu.tr, ORCID: 0000-0002-0537-3637

Citation/Atıf: Güneş, H. (2021). Türkiye'nin Dış Ticaretinde J Eğrisi Hipotezinin Analizi. Fiscaoeconomia, 5(3), 1175-1190. Doi: 10.25295/fsecon.982890 


\begin{abstract}
J Curve Hypothesis stated that the foreign trade balance may worsen at the beginning in the short term, but it will improve later in the long term after the devaluation. According to the hypothesis, the foreign trade balance will worsen because it does not react immediately against price changes in the exchange rate in the short term. However, the foreign trade balance will improve thanks to doing some regulations in the long term. The reason for that is related to Marshall-Lerner's condition. Marshall-Lerner condition means that the total export and import price elasticities is bigger than 1 which is based on J Curve.

In this study, it was investigated whether the J Curve Hypothesis is valid in Turkey.It was done the short and long term causality, cointegration and FMOLS test which showing the nondeviating coefficients of the relationship, with the data-containing the monthly time series for the period of January 2010-September 2019. As a result of the analysis, the real effective exchange rate is not a reason for export in the short term. That's why the J Curve in Turkey has reached the conclusion that is not valid. However, the real effective exchange rate is a reason for imports in the short term. In the long run, there is a causal relationship between the real Exchange rate and exports and imports. Johansen cointegration test has been carried out since the variables 1.difference and a long-term relationship between real effective exchange rates and exports and imports has been identified. According to the FMOLS estimator, a 1 unit increase in a real effective exchange rate increases export by 0.33 units and import by 0.439 units. This indicates that foreign trade deficits in Turkey will continue in the long run.
\end{abstract}

Jel Codes: F1, E4, E5.

Keywords: J curve, Exchange Rate, Export, Import, Johansen test.

\title{
1.Giriş
}

Günümüzde ülkeler dış ticaret dengesini sağlayabilmek için farklı döviz kuru politikaları uygulamışlardır. Döviz kuru oynaklığı kâr belirsizliğini arttırarak yüksek riskli ve yüksek getirili yatırımları dışlamaktadır. Çünkü döviz kuru oynaklığındaki artış, ülkelerin döviz krizine girmesine neden olmakta ve bu durum da büyüme oranlarının negatif olmasına yol açmaktadır. Böylece ülkelerin ihracatı azalmakta ve dış ticaret açıkları artmaktadır.

Sabit döviz kurunda milli paranın yabancı paralar karşısında değerinin düşürülmesini ifade eden devalüasyon, ticaret mallarının göreli fiyatını değiştirerek ihracatın artıp ithalatın azalmasına neden olur. Böylece ülkelerin dış ticaret bilançoları iyileşmektedir. Ancak bu iyileşmenin gerçekleşmesi için ihracat ve ithalat talep esnekliğinin 1'den büyük olması gerekmektedir. Diğer bir deyişle, devalüasyonun dış ticaret dengesindeki başarısı MarshallLerner koşulunun geçerli olmasına bağlıdır. Marshall-Lerner koşulu çerçevesinde dış ticaret bilançosu kısa dönemde bozulur ve uzun dönemde iyileşirse J eğrisi hipotezi geçerlidir. J eğrisi hipotezine göre, üretici ve tüketiciler döviz kurlarındaki değişen fiyatlara kısa dönemde hemen tepki veremeyecek, ancak uzun dönemde ayarlamalar sağlanarak dış ticaret dengesinde olumlu etkiler görülecektir.

Bu çalışmanın temel amacı, Türkiye'de J eğrisinin geçerli olup olmadığını test etmektir. Bu kapsamda, öncelikle teorik kısım ele alınmış ve literatür incelemesi yapılmıştır. Daha sonra da 
Türkiye' de ilgili dönemlere ait göstergeler yorumlanmıştır. Türkiye'de Ocak 2010- Eylül 2019 dönemine ait aylık veriler kullanılarak J eğrisinin geçerli olup olmadığını test eden bu çalışmada, serilerin durağanlığı sınandıktan sonra, kısa ve uzun dönemli nedensellik sonuçları verilmiştir. Daha sonra da değişkenlere ilişkin eşbütünleşme ilişkisi sınanarak değişkenlere ait uzun dönem katsayıları tahmin edilmiştir.

\section{Kavramsal Çerçeve ve Literatür Taraması}

J eğrisi hipotezi, devalüasyon işleminden sonra ticaret dengesinin önce bozulduğunu, sonra da düzeleceğini ifade etmektedir. Bu etki, ithal edilen ürünlerin yapışkan fiyatından dolayı gözlemlenmektedir (Suleman vd., 2014:210). J eğrisinin temeli, bir ülkenin para biriminin değer kaybetmesinin ticaret dengesini neden hemen iyileştirmesi gerekmediğini açıklayan Marshall-Lerner koşuluna dayanmaktadır. Devalüasyonun ticaret dengesine olumlu etki yapabilmesi için, ihracat ve ithalat fiyat esnekliğinin toplamının 1'den büyük olması gerekmektedir (Hussain ve Haque, 2014:231). J eğrisi, başlangıçta, devalüasyon yapan ülkenin ödemeler dengesinin bozulacağını; uzun vadede ise ödemeler dengesini iyileştireceğini göstermektedir (Chaulagai, 2015:19). J eğrisinin geçerliliği için, kısa dönemde döviz kuru ile ihracat arasında negatif; uzun dönemde ise devalüasyon sonucunda gerçekleşen reel döviz kuruyla ihracat arasında pozitif yönlü bir ilişki olması gerekmektedir (Kemeç ve Kösekahyaoğlu, 2015:25). Şekil 1'de J eğrisi gösterilmektedir.

\section{Şekil 1: J Eğrisi}

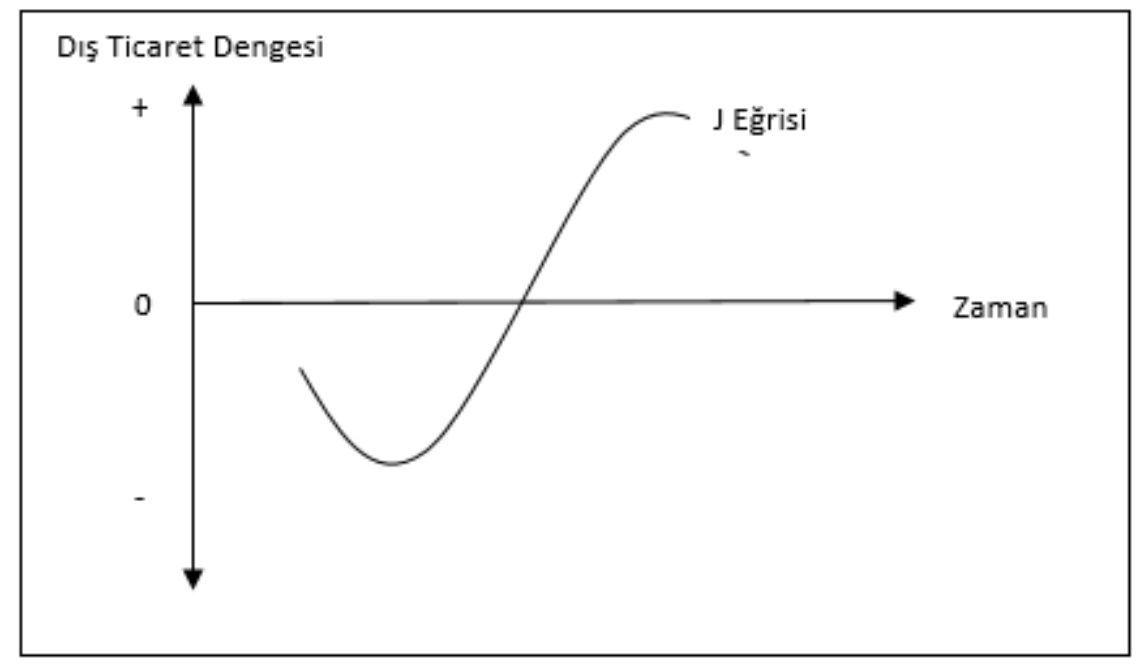

Kaynak: Şekil tarafımızca oluşturulmuştur.

Şekil 1'e göre, dikey eksende dış ticaret dengesi, yatay eksende ise zaman yer almaktadır. Buna göre, döviz kuru düştükçe, dış ticaret dengesi belli bir döneme kadar bozulmakta, ancak uzun dönemde iyileşmektedir. J eğrisi yaklaşımına göre, devalüasyon kısa dönemde dış ticaret dengesini olumsuz etkilemektedir. İhraç mallarının talebi ele alındığında, yabancıların değişen fiyatlara tepkilerinin hemen gerçeklemediği görülmekte; ihraç mallarının arzı ele alındığında ise, üretimin hemen artmadığı görülmektedir. Bu yüzden kısa dönemde fiyatlardan dolayı dış ticaret dengesi bozulmaktadır. Uzun dönemde Marshall-Lerner koşulu çerçevesinde yabancılar değişen fiyatlara tepki verecek ve talebi artacak, ülke içinde ise ithal mallara olan talep azalacaktır. Bu çerçevede uzun dönemde dış ticaret dengesi düzelmekte ve 
Güneş, H. (2021). Türkiye'nin Dış Ticaretinde J Eğrisi Hipotezinin Analizi.

Fiscaoeconomia, 5(3), 1175-1190. Doi: 10.25295/fsecon.982890

\begin{abstract}
iyileşmektedir (Demirtaş, 2014:87). J eğrisi etkisinin geçerliliği üzerine birçok çalışma yapılmıştır. Bu çalışmalar genelde az gelişmiş ülkeleri ve gelişmekte olan ülkeleri ele almaktadır. Yapılan çalışmaların yöntemi, kapsadığı dönemi ve ele aldığı ülkeler farklılaştığı için doğal olarak farklı sonuçlara ulaşılmıştır. Bu sonuçları 3 başlık altında ele alabiliriz ve bu sonuçlar kısaca şu şekilde özetlenmektedir.
\end{abstract}

Illk kategoride J eğrisi hipotezini panel data (veri) analiziyle ele alan çalışmalara yer verilmiştir. Bu çalışmalar özetlenecek olursa; Lal ve Lowinger (2002) çalışmalarında, 5 Güney Asya ülkesinde, 1985-1998 dönemi için üçer aylık verilerle J eğrisinin geçerliliğini test etmişlerdir. Nominal efektif döviz kuru ve yurtiçi-dışı gelir gibi değişkenlerin kullanıldığı bu çalışmada, J eğrisinin geçerli olduğu tespit edilmiştir. Hussain ve Haque (2014) çalışmalarında, 49 Sahra altı Afrika ülkesinde 2000-2010 dönemi için J eğrisinin etkisini incelemiş ve J eğrisinin geçerli olduğunu tespit etmiştir. Kösekahyaoğlu ve Karataşlı (2018) ise çalışmalarında, Türkiye ile 28 $A B$ üyesi için 1994-2016 dönemine ait üçer aylık verilerle J eğrisinin geçerliliğini test etmişlerdir. Çalışmanın sonucunda J eğrisinin kısa dönemde geçerli olduğu, ancak uzun dönemde geçerli olmadığı tespit edilmiştir. Son olarak Uslu (2018) ise çalışmasında, farklı gelir grubuna ait 80 ülke için 1960-2016 dönemi için Marshall-Lerner koşulu ve J eğrisinin geçerliliğini test etmişlerdir. Reel efektif döviz kuru, dış ticaret dengesi, yurtiçi-dışı milli gelir gibi değişkenlerin kullanıldığı bu çalışmada, sadece geliri yüksek olan ülkelerde, zayıf olarak J eğrisinin geçerli olduğu tespit edilmiştir.

ikinci kategoride J eğrisi hipotezini zaman serisi analizi çerçevesinde ele alan çalışmalara yer verilmiştir. Bu çalışmalardan Ur Rehman ve Afzal (2003), Pakistan'da 1972-2002 dönemi için üçer aylık veriler kullanarak J eğrisi olgusunu test etmiş ve J eğrisinin varlığına işaret etmiştir. Ancak Pakistan'da 1973-1997 dönemini ele alan Awan vd. (2012) J eğrisinin varlığının desteklenmediği sonucuna ulaşmışlardır. Suleman vd. (2014) ise Pakistan ile Suudi Arabistan'da 1973-2010 dönemi için J eğrisinin varlığının desteklenmediği sonucuna ulaşmıştır. Fiji' de J eğrisi etkisinin varlığı içinNarayan ve Narayan (2004)1970-1999 dönemi için bu ilişkiyi test etmiş; reel efektif döviz kuru ve yurtiçi-dışı gelir gibi değişkenlerin kullanıldığı bu çalışmada, J eğrisinin geçerli olduğu tespit edilmiştir. Petrovic ve Gligoric (2010) çalışmalarında, Sırbistan'da Ocak 2002- Eylül 2007 dönemine ait aylık verilerle J eğrisinin geçerliliğini test etmişlerdir. Reel efektif döviz kuru, ticaret dengesi ve reel GSYiH gibi değişkenlerin kullanıldığı bu çalışmada, kısa vadede J eğrisinin geçerli olduğu belirlenmiştir. Jamilov (2011) çalışmasında, Azerbaycan'da Ocak 2006-Aralık 2009 dönemi için aylık verilerle $\mathrm{J}$ eğrisinin etkisini incelemiştir. Reel döviz kuru, ihracat, ithalat, yurtiçi ve yurtdışı talep gibi değişkenlerin kullanıldığı bu çalışmada, J eğrisinin geçerli olduğu tespit edilmiştir. Güney Afrika'da ise J eğrisi etkisinin varlığı için Schaling ve Kabundi (2014) 1994-2011 dönemi için bu ilişkiyi tespit etmiş; reel efektif döviz kuru, ticaret dengesi ve reel GSYiH gibi değişkenlerin kullanıldığı bu çalışmada, J eğrisinin geçerli olduğu tespit edilmiştir. Amusa ve Fadiran (2019) ise, ABD ve Güney Afrika'da 1991:Q4-2016Q3 dönemine ait üçer aylık verilerle 19 sektör bazında J eğrisinin geçerliliğini test etmiş ve J eğrisinin varlığının desteklendiği sonucuna ulaşmışlardır.

Üçüncü kategoride Türkiye'de J eğrisi etkisinin geçerliliğini ele alan çalışmalara yer verilmiştir. Bu çalışmalardan Akkaya (2008), Türkiye ve dış ticaretteki partnerlerini 1990-2002 dönemi için üçer aylık veriler kullanarak J eğrisi olgusunu test etmiş ve J eğrisinin varlığının 
Güneş, H. (2021). Türkiye'nin Dış Ticaretinde J Eğrisi Hipotezinin Analizi.

Fiscaoeconomia, 5(3), 1175-1190. Doi: 10.25295/fsecon.982890

desteklenmediği sonucuna ulaşmıştır. Vergil ve Erdoğan (2009) ise, Türkiye'de 1989:1-2005:4 dönemi için üçer aylık verilerle Marshall-Lerner koşulu ve J eğrisinin geçerliliğini test etmişlerdir. Reel efektif döviz kuru, reel ihracat, reel ithalat ve reel gayrisafi yurtiçi gelir gibi değişkenlerin kullanıldığı bu çalışmada, Marshall-Lerner koşulunun sağlandığı ve J eğrisinin geçerli olduğu tespit edilmiştir. Bal ve Demiral (2012) ise, Ocak 2002-Eylül 2012 dönemi için aylık verilerle J eğrisinin etkisini incelemiş ve J eğrisinin ayarlanma sürecinde geçerli olduğunu tespit etmiştir. Kemeç ve Kösekahyaoğlu (2015) ise, 1997:1-2013:4 dönemi için çeyrek dönemlik verilerle Marshall-Lerner koşulu ve J eğrisinin geçerliliğini test etmişlerdir. Reel döviz kuru, ihracat ve ithalat fiyat endeksi gibi değişkenlerin kullanıldığı bu çalışmada MarshallLerner koşulu ve J eğrisinin varlığı gözlemlenmemiştir. Karamelikli (2016) çalışmasında, Türkiye' de Ocak 2003-Ekim 2015 dönemi için hem aylık, hem de üçer aylık verilerle J eğrisinin geçerliliğini test etmişlerdir. Reel döviz kuru, sanayi üretim endeksi ve ticaret dengesi gibi değişkenlerin kullanıldığı bu çalışmanın sonucuna göre, aylık verilerle model tahmininde eşbütünleşik bir ilişki varken; üçer aylık verilerde eşbütünleşme ilişkisi yoktur. Aynı zamanda tüm veriler için J eğrisinin varlığı gözlemlenmemiştir. Berke ve Akarsu (2017) ise, 1998-2016 dönemi için üçer aylık verilerle bu ilişkiyi incelemiş; reel efektif döviz kuru, ihracat, ithalat ve GSYiH deflatörü gibi değişkenlerin kullanıldığı bu çalışmada, J eğrisine ait bulgular gözlemlenmemiştir. Kılıç vd. (2018) ise, 1998:1-2016:3 için çeyrek dönemli verilerle ve 19902015 dönemi için yıllık verilerle J eğrisinin geçerliliğini test etmişlerdir. Reel efektif döviz kuru, dış ticaret bilançosu ve yurtiçi gelir gibi değişkenlerin kullanıldığı bu çalışmada, yıllık verilerin kullanıldığı modelde J eğrisi hipotezi geçerli değilken; üçer aylık verilerin kullanıldığı modelde J eğrisinin geçerli olduğu tespit edilmiştir. Son olarak, Eren (2019) Ocak 2004-Kasım 2018 dönemi için aylık verilerle bu ilişkiyi incelemiş; reel döviz kuru ve dış ticaret dengesi gibi değişkenlerin kullanıldığı bu çalışmada, Türkiye'nin Almanya, Çin ve Rusya ile olan dış ticaretinde J eğrisinin geçerli olmadığı belirlenmiştir.

Özetlemek gerekirse, literatür taramasında 20 farklı çalışmanın sonucu verilmiştir. Bu çalışmalardan 4'ü panel, 8'i çeşitli ülke grupları için ve diğer $8^{\prime} i$ ise Türkiye için yapılmıştır. Bu çalışmalardan 12'sinde J eğrisi etkisi gözlemlenmişken; 7'sinde J eğrisi etkisinin geçerli olmadığı belirlenmiştir. Ancak Uslu, sadece geliri yüksek olan ülkelerde zayıf olarak J eğrisinin geçerli olduğunu tespit etmiştir.

\section{Türkiye'de Döviz Kuru ile Dış Ticaret Dengesi}

Türkiye'de 1980'lere kadar uygulanan ithal ikameci sanayileşme politikası yaşanan petrol krizlerine kadar başarılı olsa da, petrol krizleri sonucunda devasa cari açık ve dış ticaret açığı vermiştir. Bu nedenle 1980'lerden sonra daha liberal politikalar benimsenmiş ve ekonomi dişa açılmıştır. 1990'lı yıllar da sıcak para ve spekülatif ataklardan dolayı finansal krizlerle geçmiş ve nitekim 2001 krizinden sonra kuru sabitleyen sistem terk edilerek yerine kurun piyasad belirlendiği esnek döviz kuru sistemine geçilmiştir (Gül ve Ekinci, 2006:165-166).

Şekil 2'de Türkiye'de Ocak 2010-Eylül 2019 arası reel efektif döviz kurunun değişimi gösterilmektedir. 


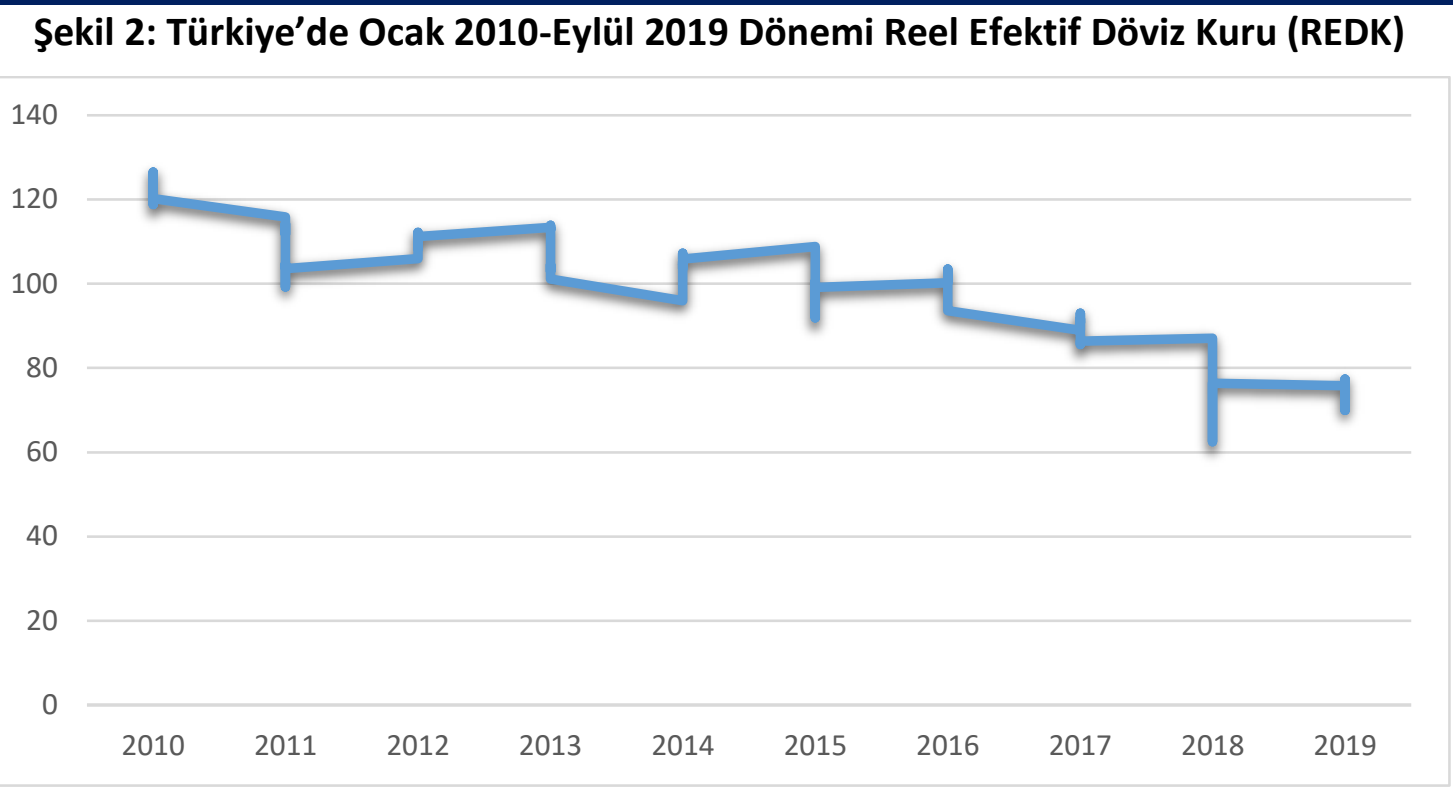

Kaynak: evds.tcmb.gov.tr

Şekil 2'ye göre, Türkiye'de 2010'dan sonra reel efektif döviz kuru düşmektedir. Ekim 2010 döneminde 126,51 ile ele alınan dönemdeki en yüksek seviyesine ulaşan reel efektif döviz kuru Ekim 2018'de 62,5'e düşmüş ve Eylül 2019 itibariyle 76,81 düzeylerine gelmiştir. Reel efektif döviz kurunun bu denli düşüşü Türk Lirası'nın reel anlamda değer kaybettiğini göstermektedir. Ayrıca reel efektif döviz kuru düştükçe, Türk malları yabancı mallar cinsinden ucuzlamıştır. Bu durum da Türk mallarının rekabet gücünü olumsuz etkilemektedir.

Ele alınan dönemlerde Türkiye'deki dış ticaret değer endeksi ise Şekil 3'de gösterilmiştir.

Şekil 3: Türkiye'de Ocak 2010-Eylül 2019 Dönemi Dış Ticaret Değer Endeksi

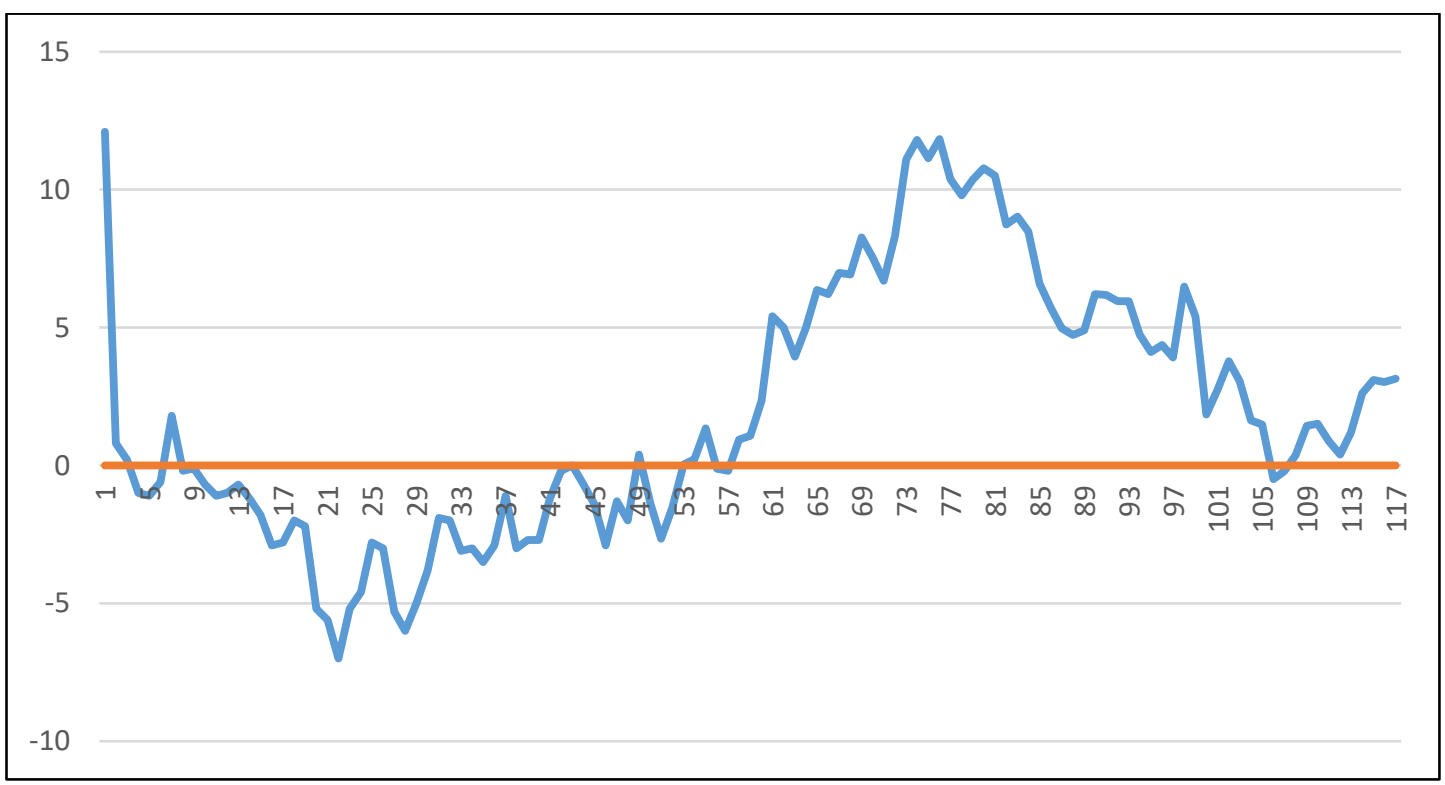

Kaynak: evds.tcmb.gov.tr 


\begin{abstract}
Şekil 3'e göre, Türkiye'deki dış ticaret değer endeksi ele alınan dönemler itibariyle başlangıçta bozulmalar gösterse de 2014 'den sonra dış ticaret dengesinde iyileşmeler görülmektedir. Bu iyileşme de TL'nin aşırı değer kaybından dolayı ithalatın daha pahalı hale gelmesi ve ihracatta Cumhuriyet tarihinin en yüksek düzeylerine çıkması da etkilidir.
\end{abstract}

\title{
4.Veri Seti, Ampirik Yöntem ve Bulgular
}

\subsection{Veri Seti ve Model}

Bu çalışmada, Türkiye için 2010:M1-2019:M9 arasındaki döneme ait aylık veriler kullanılarak J eğrisinin Türkiye'de geçerliliği test edilmiştir. Bunun için reel efektif döviz kurunun ihracat ve ithalata etkisi gözlemlenmiştir. Çalışmada kullanılan reel efektif döviz kuru göstergesi, TÜFE bazlı reel efektif döviz kuru göstermekte ve analizde "REDK" olarak yer almaktadır. İhracat ise 2010=100 olan BEC sınıflandırmasına göre yapılan dış ticaret ihracat birim değer endeksini ifade etmekte ve analizde "XBDI" olarak gösterilmektedir. Son olarak çalışmada kullanılan ithalat göstergesi ise, $2010=100$ olan BEC sınıflandırmasına göre yapılan dış ticaret ithalat birim değer endeksini ifade etmekte ve analizde "MBDI" olarak gösterilmektedir. Çalışmada kullanılan verilerin tamamı Merkez Bankası'nın veri adresi olan "evds.tcmb.gov.tr" adresinden temin edilmiştir.

Bu çalışmada tahmin edilen model (1) ve (2) nolu eşitlikte gösterilmektedir:

$$
\begin{array}{ll}
\mathrm{XBDI}_{\mathrm{t}}=\alpha+\beta_{1} \mathrm{REDK}_{\mathrm{t}}+\varepsilon_{\mathrm{t}} & \mathrm{t}=1, \ldots, \mathrm{T} \\
\mathrm{MBDI}_{\mathrm{t}}=\alpha+\beta_{1} \mathrm{REDK}_{\mathrm{t}}+\varepsilon_{\mathrm{t}} & \mathrm{t}=1, \ldots, \mathrm{T}
\end{array}
$$

Modelde bağımlı değişken, reel efektif döviz kuru; bağımsız değişkenleri ise ihracat birim değer endeksi ve ithalat birim değer endeksidir.

\subsection{Ampirik Yöntem ve Bulgular}

Zaman serilerinde, serilerin durağanlığına bakılarak model oluşturulmaktadır. Zaman serisinde ortalamayla varyans zaman içinde değişmezse ve ortak varyans iki dönem içindeki uzaklığa bağlıysa serinin durağan olduğu söylenebilmektedir (Gujarati, 1999:713). Durağan olmayan zaman serilerinde sahte regresyon sorunsalı oluşmakta ve regresyon analizinde gerçeğe aykırı sonuçlar verebilmektedir (Granger ve Newbold, 1974:111-112). Bu çalışmada birim kök testi olarak ADF ve PP birim kök testi tercih edilmiştir.

ADF testi, hata terimlerinin sabit varyansa sahip olduğunu ve hata terimleri arasında korelasyonun bulunmadığını varsaymaktadır. PP testi ise, hata terimlerinin bağımsız ve sabit varyanslı olmasını varsaymaktadır. Ayrıca PP testi, otokorelasyon problemini çözmektedir (Altun, 2017:17; Çelik ve Taş, 2007:16).

Tablo 1'de PP ve ADF birim kök test sonuçları gösterilmektedir. 
Güneş, H. (2021). Türkiye'nin Dış Ticaretinde J Eğrisi Hipotezinin Analizi.

Fiscaoeconomia, 5(3), 1175-1190. Doi: 10.25295/fsecon.982890

Tablo 1: PP ve ADF Birim Kök Testi Sonuçları

\begin{tabular}{|l|l|l|l|l|l|l|}
\hline Değişkenler & \multicolumn{1}{|c|}{ ADF } & \multicolumn{2}{|c|}{ Kritik Değer } & \multicolumn{1}{c|}{ PP } & \multicolumn{2}{l|}{ Kritik Değer } \\
& & (\%1) & $\mathbf{( \% 5 )}$ & & \multicolumn{1}{l}{ (\%1) } & \multicolumn{1}{c|}{ (\%5) } \\
\hline REDK & -1.232 & -3.488 & -2.886 & -0.875 & -3.487 & -2.886 \\
\hline XBDI & -0.613 & -3.488 & -2.886 & -1.411 & -3.487 & -2.886 \\
\hline MBDI & -0.722 & -3.488 & -2.886 & -0.832 & -3.487 & -2.886 \\
\hline$\Delta$ REDK & -8.115 & -3.488 & -2.886 & -7.819 & -3.488 & -2.886 \\
\hline$\Delta$ XBDI & -12.048 & -3.488 & -2.886 & -11.390 & -3.488 & -2.886 \\
\hline$\triangle \mathrm{MBDI}$ & -7.615 & -3.488 & -2.886 & -7.788 & -3.488 & -2.886 \\
\hline
\end{tabular}

Açıklama: $\Delta$ 1.farkı göstermektedir.

Tablo 3'e göre, reel efektif döviz kuru ile ithalat arasındaki gecikme uzunluğu 3 olarak belirlenmiştir. Gecikme uzunluğunun tespitinden sonra J eğrisinin geçerliliğini test etmek için kısa dönemli nedensellik testi yapılmıştır. Tablo 4'de J eğrisinin tespiti için reel efektif döviz kuruyla ihracat arasında kısa dönem nedensellik testi sonuçları verilmiştir.

Tablo 4: Kısa Dönem Nedensellik Testi (REDK-XBDI)

\begin{tabular}{|l|l|l|l|}
\hline Test İstatistiği & Değer & Serbestlik Derecesi & Olasılık Değeri \\
\hline F istatistiği & 0.551138 & $(2,108)$ & 0.5779 \\
\hline Ki-kare & 1.102276 & 2 & 0.5763 \\
\hline
\end{tabular}

Tablo 4'deki kısa dönem nedensellik sonuçlarına göre, kısa dönemde reel efektif döviz kuru ihracatın bir nedeni değildir. Bu yüzden J eğrisi ele alınan dönemler için Türkiye'de geçerli değildir. Tablo 5'de ise reel (efektif) döviz kuru ile ithalat arasındaki kısa dönemli nedensellik testi sonuçları verilmiştir.

Tablo 5: Kısa Dönem Nedensellik Testi (REDK-MBDI)

\begin{tabular}{|l|l|l|l|}
\hline Test İstatistiği & Değer & Serbestlik Derecesi & Olasılık Değeri \\
\hline F istatistiği & 3.319579 & $(3,105)$ & 0.0227 \\
\hline Ki-kare & 9.958736 & 3 & 0.0189 \\
\hline
\end{tabular}

Tablo 5'deki kısa dönem nedensellik sonuçlarına göre, kısa dönemde reel efektif döviz kuru ithalatın nedenidir. Reel efektif döviz kurundaki değişmeler, kısa dönemde ithalatı etkilemektedir. Tüm seriler 1.farkta durağan oldukları için uzun dönemli ilişkiyi veren eşbütünleşme testine geçilmiştir. Tablo 6'da reel (efektif) döviz kuru ile ihracat arasındaki Johansen eşbütünleşme testi sonuçları verilmiştir.

Tablo 6: Reel (Efektif) Döviz Kuru İle İhracat İçin Johansen Eşbütünleşme Testi Sonuçları

\begin{tabular}{|l|l|l|l|l|}
\hline Trace Testi & Özdeğer İstatistiği & Trace İstatistik & \%5 Kritik Değer & Olasılık Değ. \\
\hline None & 0.076995 & 12.31503 & 12.32090 & 0.0501 \\
\hline At Most & 0.030355 & 3.421592 & 4.129906 & 0.0763 \\
\hline $\begin{array}{l}\text { Maximum Eigen } \\
\text { Value Testi }\end{array}$ & Özdeğer İstatistiği & $\begin{array}{l}\text { Maximum } \\
\text { Eigen İstatistik }\end{array}$ & \%5 Kritik Değer & Olasılık Değ. \\
\hline None & 0.076995 & 8.893436 & 11.22480 & 0.1250 \\
\hline At Most & 0.030355 & 3.421592 & 4.129906 & 0.0763 \\
\hline
\end{tabular}


Tablo 6'da gösterilen veriler incelendiğinde bir yandan Trace diğer yandan Maximum Eagen değerleri için \%10 anlamlılık düzeyinde, reel (efektif) döviz kuru ile ihracat arasında bir eşbütünleşme ilişkisi görülmektedir. Bu sonuç bize, reel (efektif) döviz kuru ile ihracat arasında uzun dönemli bir ilişki olduğunu kanıtlamaktadır. Uzun dönemli ilişkinin tespitinden sonra söz konusu bu ilişkinin sapmasız katsayılarını veren FMOLS tahmincisi kullanılmıştır. Modeldeki sabit terimin, hata terimi ile bağımsız değişkenin farkları arasındaki olası ilişkinin (korelasyonun) varlığını dikkate alan FMOLS tahmincisi, modelde tahmin edilen uzun dönem parametreler ile bağımlı değişkenin bağımsızlara regres edilmesi ile bulunmaktadır (Kök ve Şimşek, 2006:7-8). Tablo 7'de reel (efektif) döviz kuru ile ihracat arasındaki FMOLS tahmincisi sonuçları verilmektedir.

Tablo 7: FMOLS Tahmincisi Sonuçları (REDK $\rightarrow$ XBDI)

\begin{tabular}{|l|l|l|l|}
\hline \multirow{2}{*}{ REDK $\rightarrow$ XBDI } & \multicolumn{3}{|c|}{$X \mathrm{XDI}_{\mathrm{t}}=\alpha+\beta_{1}$ REDK $_{\mathrm{t}}+\varepsilon_{\mathrm{t}}$} \\
\cline { 2 - 4 } & Katsayı & t-istatistiğ $\mathrm{i}$ & Olasılık Değ. \\
\hline
\end{tabular}

Tablo 7'deki FMOLS tahmincisi sonuçlarına göre, ihracat katsayısının pozitif çıkması, reel efektif döviz kurunun ihracatı pozitif yönde etkilediğini göstermektedir. FMOLS tahmincisine göre, reel efektif döviz kurundaki 1 birimlik artış ihracatı 0,33 birim arttırmaktadır. FMOLS tahmincisinin tutarlığını ölçebilmek için ise, uzun dönemli nedensellik testi yapılmıştır. Tablo $8^{\prime}$ de reel efektif döviz kuru ile ihracat arasındaki uzun dönemli nedensellik testi sonuçları verilmiştir.

Tablo 8: Uzun Dönem Nedensellik Testi (REDK-XBDI)

\begin{tabular}{|c|c|c|c|}
\hline \multicolumn{4}{|c|}{$\begin{array}{l}\mathrm{D}(\mathrm{XBDI})=\mathrm{C}(1) *(\mathrm{XBDI}(-1)-0.680261286601 * \operatorname{REDK}(-1)-32.9030983584+\mathrm{C}(2) * \mathrm{D}(\mathrm{XBDI}(-1)) \\
+\mathrm{C}(3) * \mathrm{D}(\mathrm{XBDI}(-2))+\mathrm{C}(4) * \mathrm{D}(\text { REDK}(-1))+\mathrm{C}(5) * \mathrm{D}(\text { REDK }(-2))+\mathrm{C}(6)\end{array}$} \\
\hline & Katsayı & t-istatistiği & Olasılık Değeri \\
\hline$C(1)$ & -0.033233 & -2.372462 & 0.0194 \\
\hline
\end{tabular}

Tablo 8' de gösterilen analizi sonuçlarına göre, C(1) olasılık değeri 0,05'den daha küçük olduğu için reel (efektif) döviz kuru ile ihracat arasında uzun dönemli nedensel bir ilişki vardır. Çalışmada ele alınan diğer bir model ise, reel efektif döviz kuru ile ithalat ilişkisidir. Değişkenlerin tümü 1. farkta durağan olduğundan söz konusu model için uzun dönemli ilişkiyi veren eşbütünleşme testine geçilmiştir. Tablo 9'da reel (efektif döviz) kuru ile ithalat arasındaki Johansen eşbütünleşme testi sonuçları verilmiştir.

Tablo 9: Reel Efektif Döviz Kuru İle İthalat İçin Johansen Eşbütünleşme Testi Sonuçları

\begin{tabular}{|l|l|l|l|l|}
\hline Trace Testi & Özdeğer İstatistiği & Trace İstatistik & \%5 Kritik Değer & Olasılık Değ. \\
\hline None & 0.072608 & 11.53790 & 12.32090 & 0.0674 \\
\hline At Most & 0.028162 & 3.170803 & 4.129906 & 0.0888 \\
\hline $\begin{array}{l}\text { Maximum Eigen } \\
\text { Value Testi }\end{array}$ & Özdeğer İstatistiği & $\begin{array}{l}\text { Maximum } \\
\text { Eigen İstatistik }\end{array}$ & \%5 Kritik Değer & Olasılık Değ. \\
\hline None & 0.072608 & 8.367100 & 11.22480 & 0.1523 \\
\hline At Most & 0.028162 & 3.170803 & 4.129906 & 0.0888 \\
\hline
\end{tabular}


edilmiştir. Uzun dönem nedensellik sonuçlarında ise, reel (efektif) döviz kuru ile ihracat arasında \%5 anlamlılık düzeyinde, reel efektif döviz kuru ile ithalat arasında ise \%10 anlamlılık düzeyinde uzun dönemli nedensel bir ilişki mevcuttur. Bu çalışmada Johansen eşbütünleşme testiyle modeldeki değişkenler için uzun dönemli ilişki tespit edilmiştir. Eşbütünleşme testi sonuçlarına göre, reel (efektif) döviz kuruyla ihracat ve ithalat arasında uzun dönemli eşbütünleşik bir ilişki mevcuttur. Yapılan FMOLS tahmincisiyle de, uzun dönemde reel efektif döviz kurundaki 1 birimlik artışın ihracatı 0,33 birim ve ithalatı da 0,439 birim arttırdığı tespit edilmiştir. Bu durum uzun dönemde Türkiye'de dış ticaret açıklarının devam edeceğine işaret etmektedir.

\section{Kaynakça}

Akkaya, O. (2008). “Türkiye ve Türkiye'nin Dış Ticaret Partnerleri Arasındaki İki Yanlı J Eğrisi: 1990-2002 Dönemi İncelemesi”. 2. Ulusal iktisat Kongresi, 20-22 Şubat 2008, 1-9.

Altun, N. (2017). “Türkiye'de Bütçe Açıklarının Sürdürülebilirliğinin Ampirik Olarak Analizi: 1950-2015 Dönemi". Ekonomik ve Sosyal Araştırmalar Dergisi, 13(1): 13-22.

Amusa, H. ve Fadiran, D. (2019). "The J-Curve Phenomenon: Evidence from Commodity Trade Between South Africa and the United States". Economic Research Southern Africa, ERSA Working Paper 777, April 2019.

Awan, R.U., Shahbaz, M., Sher, F. ve Javed, K. (2012). "Does J-Curve Phenomenon Exist in Pakistan? A Revisit". Interdisciplinary Journal Of Contemporary Research In Business, 3(9): 1456-1467.

Bal, H. ve Demiral, M. (2012). “Reel Döviz Kuru ve Ticaret Dengesi: Türkiye'nin Almanya ile Ticareti Örneği (2002.01-2012.09)". Çukurova Üniversitesi IiBF Dergisi, 16(2): 45-64.

Berke, B. ve Akarsu, G. (2017). "Türkiye İçin J Eğrisi Analizi”. III. International Balkan and Near Eastern Social Sciences Congress Series-Edirne, March 4-5: 195-202.

Chaulagai, M.K. (2015). "Testing the J-Curve Hypothesis: A Case of Nepal". NRB Economic Review, 27(1): 17-27.

Çelik, T.T. ve Taş, O. (2007). "Etkin Piyasa Hipotezi ve Gelişmekte Olan Hisse Senedi Piyasaları”. iтÜ Sosyal Bilimler Dergisi, 4(2): 11-22.

Demirtaş, G. (2014). “Türkiye ve Almanya Arasındaki Dış Ticaret Dengesinin Sınır Testi Yaklaşımıyla İncelenmesi". Erciyes Üniversitesi iktisadi ve Idari Bilimler Fakültesi Dergisi, 43:. 83-106.

Eren, O. (2019). "Reel Döviz Kurunun İkili Dış Ticarete Etkileri: Türkiye Örneği”. Uluslararası Sosyal Araştırmalar Dergisi, 12(63): 1038-1056.

Gül, E. ve Ekinci, A. (2006). "Türkiye'de Reel Döviz Kuru ille İhracat ve İthalat Arasındaki Nedensellik illişkisi: 1990 - 2006". Dumlupınar Üniversitesi Sosyal Bilimler Dergisi, 16:165 -190.

Granger, C.W.J. ve Newbold, P. (1974). "Spurious Regressions in Econometrics". Journal of Econometrics, 2: 111-120, NorthHolland Publishing Company. 
Gujarati, D. N. (2009), "Temel Ekonometri”. Çev., Gülay G. Şenesen ve Ümit Şenesen, Literatür Yayıncilık.

Hussain, M.E. ve Haque, M. (2014). "Is the J-Curve a Reality in Developing Countries". Journal of Economics and Political Economy, 1(2): 231-240.

Jamilov, R. (2011). "J-Curve Dynamics and the Marshall-Lerner Condition: Evidence from Azerbaijan". MPRA, November 2011, Paper No:36799

Karamelikli, H. (2016). "Türkiye'nin Dış Ticaret Dengesinde J-Eğrisi Etkisi”. Insan ve Toplum Bilimleri Araştırmaları Dergisi, 5(3): 389-402.

Kemeç, A. ve Kösekahyaoğlu, L. (2015). "J Eğrisi Analizi Ve Türkiye Üzerine Bir Uygulama”. Uluslararası Iktisadi ve Idari Bilimler Dergisi, 2(1): 1-29.

Kılıç, R., Özbek, R.i. ve Çifçi, ì. (2018). "Türkiye İçin J-Eğrisi Hipotezinin Geçerliliği: Ardl Sınır Testi Yaklaşımı". International Journal of Disciplines in Economics\& Administrative Sciences Studies, 4(7): 112-128.

Kök, R. ve Şimşek, N. (2006). “Endüstri-içi Dış Ticaret, Patentler ve Uluslararası Teknolojik Yayılma". http://debis.deu.edu.tr/userweb/recep.kok/endustriici_patent.pdf

Kösekahyaoğlu, L. ve Karataşlı, İ. (2018). “Türkiye - AB Dış Ticaretinde J Eğrisi Etkisi: 1994-2016 Dönemi Üzerine Ampirik Bir İnceleme". Süleyman Demirel Üniversitesi iiBF Dergisi, 23: 831-844.

Lal, A.K. ve Lowinger, T.C. (2002). "Nominal Effective Exchange Rate and Trade Balance Adjustment in South Asia Countries". Journal of Asian Economics, 13(3): 371-383.

Narayan, P.K. ve Narayan, S. (2004). "The J-Curve: Evidence from Fiji". International Review of Applied Economics, 18(3): 369-380.

Petrovic, P. ve Gligoric, M. (2010). "Exchange Rate and Trade Balance: J-curve Effect". Panoeconomicus, 1: 23-41.

Schaling, E. ve Kabundi, A. (2014). "The Exchange Rate, The Trade Balance and The J-Curve Effect In South Africa". South African Journal of Economics and Management Sciences (SAJEMS), 17(5):601-608.

Suleman, S., Cheema, A.R., Riaz, M.F., Yousaf, M.M. ve Shehzadi, A. (2014). "Time Series Investigation of J-Curve of Pakistan with Saudi Arabia". Journal of Finance and Economics, 2(6): 210-214.

Ur Rehman, H. ve Afzal, M. (2003). "The J Curve Phenomenon: An Evidence From Pakistan". Pakistan Economic and Social Review, 41(1-2): 45-58.

Uslu, H. (2018). “Marshall - Lerner Koşulu Ve J Eğrisi Hipotezinin Geçerliliği: Farklı Gelir Gurubu Ülkeleri İçin Karşılaştırmalı Bir Analiz". International Journal of Academic Value Studies, 4(20): 550-561.

Vergil, H. ve Erdoğan, S. (2009). “Döviz Kuru-Ticaret Dengesi illişkisi: Türkiye Örneği”. ZKÜ Sosyal Bilimler Dergisi, 5(9): 35-57. 
Güneş, H. (2021). Türkiye'nin Dış Ticaretinde J Eğrisi Hipotezinin Analizi.

Fiscaoeconomia, 5(3), 1175-1190. Doi: 10.25295/fsecon.982890

Etik Beyanı: Bu çalışmanın tüm hazırlanma süreçlerinde etik kurallara uyulduğunu yazarlar beyan eder. Aksi bir durumun tespiti halinde Fiscaoeconomia Dergisinin hiçbir sorumluluğu olmayıp, tüm sorumluluk çalışmanın yazarlarına aittir.

Ethics Statement: The authors declare that ethical rules are followed in all preparation processes of this study. In case of detection of a contrary situation, Fiscaoeconomia has no responsibility and all responsibility belongs to the authors of the study. 
Güneş, H. (2021). Türkiye'nin Dış Ticaretinde J Eğrisi Hipotezinin Analizi.

Fiscaoeconomia, 5(3), 1175-1190. Doi: 10.25295/fsecon.982890

The Analysis of J Curve Hypothesis on Turkey's Foreign Trade

Hakan GÜNEŞ

\section{Extended Abstract}

Today, countries have implemented different exchange rate policies in order to maintain their foreign trade balance. Exchange rate volatility increases profit uncertainty and excludes highrisk and high-return investments. Because the increase in exchange rate volatility causes countries to enter into a currency crisis, and this leads to negative growth rates. Thus, exports of countries decrease and foreign trade deficits increase.

Devaluation, which expresses the decrease in the value of the national currency against foreign currencies at a fixed exchange rate, changes the relative price of trade goods, causing exports to increase and imports to decrease. Thus, the foreign trade balance of the countries is improving. However, for this improvement to take place, the demand elasticity of export and import must be greater than 1 . In other words, the success of devaluation in the foreign trade balance depends on the validity of the Marshall-Lerner condition. If the foreign trade balance deteriorates in the short run and improves in the long run, the J-curve hypothesis is valid within the framework of the Marshall-Lerner condition. According to the $\mathrm{J}$ curve hypothesis, producers and consumers will not be able to react immediately to changing prices in exchange rates in the short run, but positive effects will be seen in the foreign trade balance by making adjustments in the long run.

According to the J-curve approach, devaluation negatively affects the foreign trade balance in the short run. Considering the demand for export goods, it is seen that the reaction of foreigners to changing prices is not immediate; When the supply of export goods is considered, it is seen that production did not increase immediately. Therefore, in the short run, the foreign trade balance deteriorates due to prices. In the long run, within the framework of Marshall-Lerner condition, foreigners will react to changing prices and their demand will increase, while domestic demand for imported goods will decrease. In this framework, the foreign trade balance improves and improves in the long term (Demirtaş, 2014:87). Many studies have been conducted on the validity of the J-curve effect. These studies generally deal with underdeveloped and developing countries. Different results were obtained because the method used, the year and the countries covered were different. We can consider these results in 3 categories and these results are briefly summarized as follows.

In the first category, studies dealing with the J-curve effect with panel data analysis are included. To summarize these 4 studies; Lal and Lowinger (2002) tested the validity of the J curve with quarterly data for the 1985-1998 period in 5 South Asian countries. In this study, in which variables such as nominal effective exchange rate and domestic-foreign income were used, it was determined that the J curve was valid. Hussain and Haque (2014) examined the effect of the J curve for the period 2000-2010 in 49 sub-Saharan African countries and found that the J curve was valid. Kösekahyaoğlu and Karataşlı (2018), on the other hand, tested the validity of the J curve with quarterly data for the period 1994-2016 for Turkey and 28 EU members. As a result of the study, it has been determined that the J curve is valid in the short run, but not in the long run. Finally, Uslu (2018) tested the validity of the Marshall-Lerner condition and $\mathrm{J}$ curve for the period 1960-2016 for 80 countries belonging to different income 
Güneş, H. (2021). Türkiye'nin Dış Ticaretinde J Eğrisi Hipotezinin Analizi.

Fiscaoeconomia, 5(3), 1175-1190. Doi: 10.25295/fsecon.982890

groups. In this study, in which variables such as real effective exchange rate, foreign trade balance, and domestic-foreign national income were used, it was determined that the weak J curve was valid only in high-income countries.

In the second stage, studies dealing with time series for different countries are included. Among these studies, Ur Rehman and Afzal (2003) tested the J curve phenomenon using quarterly data for the 1972-2002 period in Pakistan and pointed out the existence of the J curve. However, dealing with the 1973-1997 period in Pakistan, Awan et al. (2012) concluded that the existence of the J curve is not supported. Suleman et al. (2014) concluded that the existence of the J curve for the 1973-2010 period in Pakistan and Saudi Arabia is not supported. For the existence of the J curve effect in Fiji, Narayan and Narayan (2004) tested this relationship for the 1970-1999 period; In this study, in which variables such as real effective exchange rate and domestic-foreign income were used, it was determined that the J curve was valid. In their study, Petrovic and Gligoric (2010) tested the validity of the J curve with monthly data from January 2002 to September 2007 in Serbia. In this study, in which variables such as real effective exchange rate, trade balance and real GDP are used, it is determined that the $J$ curve is valid in the short run. Jamilov (2011) examined the effect of the J curve with monthly data for the period January 2006-December 2009 in Azerbaijan. In this study, in which variables such as real exchange rate, export, import, domestic and foreign demand were used, it was determined that the J curve was valid. For the existence of the Jcurve effect in South Africa, Schaling and Kabundi (2014) determined this relationship for the 1994-2011 period; In this study, in which variables such as real effective exchange rate, trade balance and real GDP were used, it was determined that the J curve was valid. Amusa and Fadiran (2019), on the other hand, tested the validity of the J curve on the basis of 19 sectors with quarterly data for the period 1991:Q4-2016Q3 in the USA and South Africa, and concluded that the existence of the $J$ curve is supported.

In the third stage, studies dealing with the validity of the J-curve effect in Turkey are included. From these studies, Akkaya (2008) tested the J curve phenomenon using quarterly data for Turkey and its foreign trade partners for the period 1990-2002 and concluded that the existence of the J curve is not supported. On the other hand, Vergil and Erdoğan (2009) tested the validity of Marshall-Lerner condition and J curve with quarterly data for the period 1989:12005:4 in Turkey. In this study, in which variables such as real effective exchange rate, real exports, real imports and real gross domestic income were used, it was determined that the Marshall-Lerner condition was met and the J curve was valid. Bal and Demiral (2012), on the other hand, examined the effect of the J curve with monthly data for the January 2002September 2012 period and found that the J curve was valid during the adjustment process. Kemeç and Kösekahyaoğlu (2015), on the other hand, tested the validity of Marshall-Lerner condition and J curve with quarterly data for the period 1997:1-2013:4. In this study, in which variables such as real exchange rate, export and import price index were used, the existence of Marshall-Lerner condition and J curve was not observed. In their study, Karamelikli (2016) tested the validity of the J curve with both monthly and quarterly data for the period January 2003-October 2015 in Turkey. According to the results of this study, in which variables such as real exchange rate, industrial production index and trade balance are used, there is a cointegrated relationship between monthly data and model estimation; There is no cointegration relationship in quarterly data. At the same time, the existence of the J curve was 
Güneş, H. (2021). Türkiye'nin Dış Ticaretinde J Eğrisi Hipotezinin Analizi.

Fiscaoeconomia, 5(3), 1175-1190. Doi: 10.25295/fsecon.982890

not observed for all data. Berke and Akarsu (2017), on the other hand, examined this relationship with quarterly data for the 1998-2016 period; In this study, in which variables such as real effective exchange rate, export, import and GDP deflator were used, the findings of the J curve were not observed. Kilic et al. (2018), on the other hand, tested the validity of the J curve with quarterly data for the period 1998:1-2016:3 and annual data for the period 1990-2015. In this study, in which variables such as real effective exchange rate, foreign trade balance and domestic income are used, the $\mathrm{J}$ curve hypothesis is not valid in the model using annual data; It has been determined that the $\mathrm{J}$ curve is valid in the model using quarterly data. Finally, Eren (2019) examined this relationship with monthly data for the period January 2004November 2018; In this study, in which variables such as real exchange rate and foreign trade balance were used, it was determined that the J curve was not valid in Turkey's foreign trade with Germany, China and Russia.

In this study, the validity of the J curve was tested by using monthly data for the period of January 2010-September 2019 in Turkey. In the study, first of all, the stationarity of the series was tested and ADF and PP unit root tests were applied. Since all the series are stationary at the 1st difference, Johansen cointegration test is used to determine the long-term relationship and FMOLS estimator is used to estimate the unbiased coefficients of the long-term relationship. In addition, in the study, short-term causality was examined to test the validity of the $J$ curve, and then the relationships between the long-term causality results and the variables were determined.

According to the results of the study, it has been concluded that the J curve is not valid in Turkey since the real effective exchange rate is not a reason for exports in the short run. Then, another variable, imports, was examined and it was determined that the real effective exchange rate was the cause of imports in the short run. In the long-term causality results, there is a long-term causal relationship between the real effective exchange rate and exports at the $5 \%$ significance level, and between the real effective exchange rate and imports at the $10 \%$ significance level. In this study, the long-term relationship between the variables was determined by the Johansen cointegration test. According to the results of the cointegration test, there is a long-run cointegrated relationship between the real effective exchange rate and exports and imports. With the FMOLS estimator, it was determined that a 1-unit increase in the real effective exchange rate increased exports by 0.33 units and imports by 0.439 units. This indicates that foreign trade deficits in Turkey will continue in the long run. 